\title{
Play Hard, Shirk Hard? The Effect of Bar Hours Regulation on Worker Absence*
}

\author{
COLIN P. GREEN $\uparrow$ and MARIA NAVARRO PANIAGUA $\uparrow$
}

$\uparrow$ Economics Department, Lancaster Management School, Lancaster University, Lancaster, LA1 4YX

(e-mail: c.p.green@lancaster.ac.uk, m.navarropaniagua@lancaster.ac.uk)

\begin{abstract}
The regulation of alcohol availability has the potential to influence worker productivity. This paper uses legislative changes in bar opening hours to provide a potential quasi-natural experiment of the effect of alcohol availability on working effort, focusing on worker absenteeism. We examine two recent policy changes, one in England/Wales and one in Spain that increased and decreased opening hours, respectively. We demonstrate a robust positive causal link between opening hours and absenteeism, although short-lived for Spain. The effect is long lasting for the UK where we provide evidence which suggests that increased alcohol consumption is a key mechanism.
\end{abstract}

JEL Classification: J22, K32

KEY WORDS: Labour Supply, Absenteeism, Alcohol Policy

\footnotetext{
* The authors would like to thank the editor and two anonymous referees, Silke Anger, Steve Bradley, Paul Devereux, Mirko Draca, Javier Gardeazabal, Juan Ramon Garcia, John Heywood, Gareth Leeves, Owen O’Donnell, Efthymios Pavlidis, Aydogan Ulker, Ian Walker, Anwen Zhang, seminar participants at the University of Wisconsin-Milwaukee, Kings College London, RWI-Essen, participants at the $4^{\text {th }}$ Annual Meeting on the Economics of Risky Behaviours, the $11^{\text {th }}$ IZA/SOLE Transatlantic Meeting, the 2012 EEA conference in Malaga, the 2012 EALE conference in Bonn and the 2013 RES conference in Royal Holloway for helpful comments. María Navarro gratefully acknowledges financial support from the Spanish CYCIT Research Project ECO2008-06395-C05-03/ECON. Corresponding author: Colin Green, Economics Department, Lancaster University, Lancaster, LA1 4YX, UK. e-mail: c.p.green@ lancaster.ac.uk. Maria Navarro, Economics Department, Lancaster University, Lancaster, LA1 4YX, UK, e-mail: m.navarropaniagua @ lancaster.ac.uk.

This study analysed existing data that are available from the UK Data Archive. Further documentation about the data that were used in this paper is available from the Lancaster University data archive at http://dx.doi.org/10.17635/lancaster/researchdata/42. The usual disclaimer applies.
} 


\section{Introduction}

The regulation of alcohol consumption remains a highly contentious area of public policy and has generated a large literature in both public health and economics (see Anderson et al., 2009 and Carpenter and Dobkin, 2011a for recent reviews). Policies aimed at regulating alcohol are numerous including taxation, minimum pricing, age based restrictions, placebased restrictions and restrictions on the timing of sales. Timing restrictions can take many forms, including restrictions on permissible days and hours of alcohol availability both on and off premises. For instance, day restrictions include laws that prevent Sunday sales of alcohol in the United States and Australia; and restrictions on trading on specific days that were previously common in Scandinavia (Grönqvist and Niknami, 2014; Heaton, 2012). This type of regulation appears to influence consumption behaviour. For instance, Carpenter and Eisenberg (2009) show that allowing Sunday sales in Ontario, Canada, increased Sundayspecific drinking by $7-15 \%$, mainly in the form of substitution from drinking on Saturdays. At the same time, restrictions on the timing of on premise drinking are the norm, but with a wide variation in actual opening hours across jurisdictions. The aim of these laws is not solely to restrict alcohol availability, but also to reduce negative externalities from leisure behaviour such as noise pollution and disruption to residents near venues. This regulation of opening hours has been shown to influence a range of health and socio-economic outcomes including alcohol consumption (Bernheim, Meer and Novarro, 2012), traffic accidents (Green et al., 2014; Vingilis et al., 2005; Smith 1990) and crime (Carpenter and Dobkin, 2011b; Chikritzhs and Stockwell 2002; Biderman et al., 2010; Hough and Hunter, 2008 and Humphreys and Eisner 2010).

While mainly aimed at reducing social externalities associated with excessive consumption, alcohol regulations also have the potential to influence labour market outcomes. In terms of alcohol taxation this idea has attracted some attention. For instance, Johansson et al (2014) examine the effect of a cut in alcohol taxation in Finland which led to large differences in alcohol prices between Finland and Sweden. They show that this had a weak effect on mortality and alcohol related illnesses but increased workplace absenteeism, a $5 \%$ increase for males and a $13 \%$ increase for females in Swedish regions near the Finnish border when compared to Swedish regions that are over $100 \mathrm{~km}$ away from the border. In contrast, Dave and Kaestner (2002) find no evidence that alcohol taxes are related to labour market outcomes such as employment, hours of work and wages in the US. 
Restrictions on opening hours also have the potential to influence labour market outcomes, but this has received little attention to date. Traditionally, the effect of government regulation of leisure is thought of through the lens of income and substitution effects (see for instance Burtless and Hausman, 1978; Blundell, Duncan and Meghir, 1998). However, individual labour supply behaviour could be influenced directly by leisure regulation if, for instance, it affects the temporal proximity of leisure consumption and working hours (Biddle and Hamermesh, 1990). Moreover, the timing of consumption could also have spill-over effects into working hours when intoxicating substances like alcohol are involved. Along these lines, previous evidence suggests that alcohol consumption is linked to absenteeism (Balsa and French, 2010; Johansson et al., 2008; and Norstrom, 2006).

This paper investigates how the regulation of licensed hours at establishments that serve alcohol influences working hours, focusing primarily on worker absenteeism. While, there is no existing evidence along these lines, it has been previously demonstrated that other forms of alcohol legislation such as minimum drinking ages and reductions in alcohol taxation can influence workforce productivity (Carpenter and Dobkin, 2011a; Johansson et $a l ., 2014)$. We use recent changes in legal pub and club (herein bars for simplicity) opening hours in the UK and Spain as 'quasi-natural' experiments to identify the effect of on-premise alcohol availability on absence. ${ }^{1}$ These two legislative changes provide a nice point of comparison, as one involves a substantial liberalisation of opening hours (the UK) while the other involves a similarly substantial decrease in opening hours (Spain). These changes have the potential to affect working behaviour due to the proximity of leisure activity to normal working hours, but also through the timing of the consumption of alcohol.

To summarize our results, we demonstrate a causal link between bar opening hours and worker absenteeism, longer opening hours increase absence. In terms of the direction of the effects, the results are symmetric: increasing opening hours (UK) increases absenteeism, decreasing opening hours (Spain) reduces absenteeism. We identify the causal effect of opening hours on absenteeism using difference in difference approaches. In addition, we demonstrate the robustness of our results to standard concerns derived from applying a difference-in-difference methodology such as violations of the common trend assumption and the suitability of the control group. While, the UK policy effect appears robust, for Spain the

\footnotetext{
${ }^{1}$ We treat absenteeism as a proxy for worker effort (Audas et al., 2004).
} 
effect appears to be relatively short-lived and concentrated amongst early adopting regions. Finally, we provide evidence on the mechanisms through which the policy influenced worker absenteeism for the UK. This evidence is suggestive of a central role for increased on premise alcohol consumption.

\section{Data and Institutional Background}

\section{Changes in Drinking Laws, UK and Spain}

The identification strategy in this paper is based on two legislative changes which form the basis of a difference in differences estimation approach. The changes were an extension of legal closing hours in two constituent parts of the UK, England and Wales and a reduction in the permitted hours that bars could remain open in Spain. For England and Wales, prior to the legislative change pubs were not allowed to stay open (and serve alcohol) after 11:00 pm. Following the Licensing Act of 2003, licensed venues could apply to remain open for longer up to a maximum of 5:00 am. This change reflected a view that the prior regime was needlessly restrictive and that shorter opening hours may encourage binge drinking insofar as individuals would increase the speed of alcohol consumption (IAS, 2007). This legislative change came into effect across all of England and Wales as of the $24^{\text {th }}$ of November 2005: as at $1^{\text {st }}$ April 2006 (the first available official statistics) some 50114 venues had been granted these licenses. By 2010 this number had increased to 78879 venues. Hence, the main expansion occurred in the initial time period that the legislation was enacted.

In the Spanish case, the reduction in opening hours consisted of a requirement that licensed venues, such as bars, were legally required to close at 3:00 am (with some minor variation). Prior to the legislative change the legal closing time was $6 \mathrm{am}$, and the majority of drinking venues did not close until this time. Unlike England and Wales, this change primarily reflected concerns over noise pollution and general disruption to residents near licensed venues. This legislation was enacted in different periods regionally across Spain, and varied in terms of the actual new time of closing ranging from 2:00 am to 3:30 am. The differential timing of the reform in Spain reflects the devolution of certain legislative powers to regional levels. In the case of public entertainment and recreation policy, devolution was completed by 1996. This meant that whilst the key legislative change in opening hours was mandated at a federal level, a degree of regional autonomy in the timing of the adoption and actual closing times was permitted. We investigate the potential for bias of our results from 
non-random timing of adoption later. Importantly, other related policies, such as alcohol taxation and prices, age based regulation, location restrictions and drink driving policies and sanctions are enacted only at a national level. This limits the potential of our policy estimates to be influenced by confounding changes in other related alcohol policy. Specifics of the actual legislative changes are reported in online appendix Table A1. This data shows the quarter and year the reform came into force in Spain in each of the regions, and highlights some variation in closing times. For completeness the England/Wales legislative change is reported at the bottom of Table A1.

The margin at which these changes occurred means that the policy changes may affect different types of individuals in the UK and Spain. Extending hours from $11 \mathrm{pm}$ is likely to hit a broad cross-section of individuals. In contrast, reductions from 6am to $3 \mathrm{am}$ are more likely to be binding for younger individuals: they are simply more likely to attend bars at these times.

\section{Data}

The two main data sources used in this paper, the UK Longitudinal Labour Force Survey (UK LFS) and the Spanish Labour Force Survey (SLFS), are very similar in their basic structure. Both are quarterly representative surveys that provide a range of information on individual and work characteristics. A key feature of the data for our purposes is that they both have an internationally consistent definition of absence (Barmby, Ercolani and Treble, 2002), which we describe in more detail below.

For the UK, we use the version of the LFS that follows individuals for 5 consecutive quarters from entry. It is a rotating panel insofar as every quarter one cohort enters and another exits (after their 5 quarters). We focus on the period 1997-2008. This provides 846,106 observations for 218,405 different individuals. The SLFS is a quarterly survey from which we have data available from the $1^{\text {st }}$ quarter of 1996 to the $4^{\text {th }}$ quarter of 2007 . It is a repeated cross-section and our estimating sample consists of 1,993,260 observations.

We use information on usual and actual hours of work per week to generate two indicators of weekly absence. ${ }^{2}$ The first is the hours a worker is absent per week $\left(A_{i t}\right)$. We

\footnotetext{
${ }^{2}$ One might expect the effect of alcohol liberalisation on absenteeism to be concentrated on particular days of the week, however data on the specific timing of absence within the week is not available in our data.
} 
calculate this variable as the difference between usual hours $\left(H_{i t}{ }_{i t}\right)$ and actual hours $\left(H_{i t}^{e}\right)$ such that $A_{i t}=H_{i t}^{u}-H_{i t}^{e}$. For ease of interpretation we multiply this number by 60 so that the estimated coefficients are in terms of minutes of absence. The second variable is the absence rate $\left(A R_{i t}\right)$. This is defined as the ratio of the hours reported absent to contractual hours in the reference week $A R_{i t}=A_{i t} / H_{i t}^{u}$. A potential issue is that these measures of absenteeism may be affected by changes in time at work that are outside of the control of the worker and as a result should not be readily affected by changes in drinking laws. Both the UK LFS and the SLFS contain information on why hours varied in the reference week. This allows us to construct absence measures that are more narrowly defined, excluding (for instance) variation due to flexible working hours, variations due to changes in jobs, training episodes, industrial disputes, vacations and public holidays. Importantly, our key estimates are robust to using these narrower definitions of absence and this is discussed in more detail in the results section.

\section{INSERT FIGURE 1}

Figures 1 and 2 provide some illustrative information on absence trends in our two settings. Figure 1 shows absence trends before and after the policy changes for England/Wales and Scotland/Northern Ireland, respectively. This provides some indication that the absence trends for England/Wales and Scotland/Northern Ireland follow similar patterns prior to the policy change. After the policy there is a clear divergence in behaviour; workers in England/Wales take relatively more absence, while for Scotland/Northern Ireland the trend appears stable.

\section{INSERT FIGURE 2}

Figure 2 plots similar data for Spain. A complication here in terms of visualisation is that we have variation in the timing of policy implementation by region. Since reduced hours occur in regions across different times we follow the approach of Ayres and Levitt (1998) and standardize the implementation timing of the policy to zero (for four quarters). As a result the horizontal axis provides the periods from pre to post reduction in opening hours. For instance 0 is both the year from the first quarter of 2003 for Andalusia, the year from the

\footnotetext{
${ }^{3}$ We treat usual hours as synonymous with contractual hours. This is similar in spirit to the approach used in previous research by Barmby et al (2002), Lozano (2010) and Green and Navarro (2012), among others.
} 
$1^{\text {st }}$ quarter of 2006 for Aragon and so forth. While period t- 1 in Figure 2 corresponds to the 4 quarters of absence for the year before implementation for each of the 11 regions that reduce opening hours during our sample period. For comparison, Figure 2 also reports a simple average of minutes of absence for those 7 regions that do not reduce opening hours in our sample period.

Both data sets have quite a rich set of potential control variables, including many of the candidates that have been shown to be important determinants of worker absenteeism in previous research. Thus, we incorporate socio-demographic variables, including the age and the age squared, gender, marital status and education level. We also include variables which denote whether the individual works in the public sector, the type of contract, industry dummies, occupation dummies and size of the firm/establishment. Finally, region, year and quarter dummies are introduced to take account of regional, time and seasonal variation.

An important issue is that certain individuals' working hours may be directly affected by the change in drinking laws, most notably those who work in bars. We exclude all individuals working in these establishments, and to be especially sure, those working in allied industries such as hotels and restaurants. In addition, we exclude workers who are under the minimum legal drinking age of 18 . Online appendix Table A2 provides summary statistics for the resultant samples for both the UK and Spain.

\section{Methodology and Identification}

We estimate the effect of changes in opening hours on absenteeism using variants of the following reduced form model:

$$
A_{i j t}=\alpha+\beta \text { Policy }_{i j t}+\gamma X_{i j t}+\mu_{j}+\tau_{t}+t \mu_{j}+\varepsilon_{i j t}
$$

where $A_{i j t}$ corresponds to the minutes of absence of worker $i$ in region $j$ in period $t$.

In the UK setting, Policy ${ }_{i j t}$ equals one for treated individuals (workers residing in England or Wales) in the post-treatment period, with extended bar opening hours (after the $24^{\text {th }}$ of November 2005) and zero otherwise. The OLS estimate of $\beta$ in equation (1) is equivalent to the Differences-in-Differences (DD) estimator and this provides an estimate of the increase in absence caused by the change in licensing laws for workers in England or Wales compared to those living in Scotland or Northern Ireland. In the UK-LFS we can 
observe the week of interview and thus we can identify the policy effect separately from quarter controls aimed to pick up seasonality in absence.

For Spain, we have regional and time variation in the adoption of the legislative change. We observe 11 regions (out of 18 in total) closing bars earlier in different periods. The models are identified using regional variation in the timing of policy adoption, controlling for differences across regions that were not treated over the same time period. In Spain Policy ${ }_{i j t}$ takes the value 1 if the worker is observed in region $j$ and at time $t$ that region has reduced drinking hours, its accompanying parameter is equivalent to the Differences-inDifferences estimator.

In both countries, region fixed effects $\mu_{j}$ are included for the model to account for persistent unobserved regional characteristics that may be correlated with the timing of the introduction of the policy and with absenteeism. There could for instance be differences in absence patterns between regions in the south and in the north. In a similar way, the year fixed effects $\tau$, removes national time variation in absenteeism.

The key identifying assumption for any DD strategy is that the outcome in the treatment and the control group would follow the same trend in the absence of treatment. At first glance, the pre-treatment trends across treated and comparison groups displayed for the UK in Figure 1 and for Spain in Figure 2 appear similar. Nonetheless, differences in prepolicy trends may confound our estimates of the policy effect. As a result, we extend our specification further by re-estimating our main models incorporating region-specific linear time trends $t \mu_{j}$. We do this by interacting the dummy for each region with a linear time trend that equals 1-4 for the first year 5-8 for the second year and so forth. Our main results are robust to replacing this quarterly time trend with a yearly time trend, along with its interaction with region dummies.

A standard concern in the literature on policy evaluation using difference in difference approaches is that spurious inference may result if the error structure is not modelled correctly. Specifically, a concern in our case would be the assumption that the error term is normally distributed within the regions in which our workers are embedded. This may lead to standard errors which are artificially low. One approach is to introduce robust standard errors clustered at the policy level. For Spain, we observe 18 regions, with 11 changing policy within our sample period. However, for the UK, while we observe 20 regions, the policy only 
varies at the country level. Standard results for the introduction of clustered standard errors with small numbers of groups are not encouraging (Bertrand et al., 2004). As an alternative for the UK we adopt the approach suggested by Cameron et al., (2008) and estimate our standard errors using a wild bootstrap procedure by cluster (policy level) that aims to address this issue. A related concern is that while using longer panels of data help to address concerns regarding spurious estimates in DD models, the presence of serial correlation in the dependent variable will downwardly bias standard errors. In additional robustness checks we also adopt the approach suggested by Bertrand et al (2004) and collapse our data into pre and post policy periods and re-estimate our models.

Finally, in all models we estimate variants of (1) where the dependent variable is the absence rate (AR) as defined above. This dependent variable is more flexible insofar as it explicitly allows for variations in contractual hours. This variable is censored at zero and many workers are observed at this bound. As a result, we estimate these models by Tobit. This has the advantage of being a more efficient estimator, but will lead to policy estimates which are not directly comparable to the minutes absence models in terms of magnitude of effect. To aid this comparison we also report OLS estimates of the effect of changing drinking hours on the absence rate.

\section{Results}

\section{INSERT TABLE 1}

Table 1 provides the reduced form estimates of the effect of the drinking law regulation in England/Wales on worker absenteeism. Three groups of estimates are reported, OLS estimates of minutes difference along with Tobit and OLS estimates of the absence rate. A vector of standard controls is included. The estimates for these controls are not reported but are available upon request. It is worth noting that for both the UK and Spain estimates of the control variables largely follow those previously reported in the literature on absence. For instance, temporary workers take less absence (Bradley, Green and Leeves, 2014; Ichino and Riphahn, 2005), public sector workers, female and married workers take more absence (Barmby, Orme and Treble, 1991).

Our main finding is that there is an impact of the legislative change on worker absenteeism in England and Wales. The estimates in the first panel of Table 1 show that increasing opening hours increased worker absence by approximately 1.4 percentage points 
and lead to an increase in time lost through absence of 5.59 minutes per week per worker. For completeness and to aid comparability we also report the OLS estimates of the policy effect on the absence rate. These estimates are small, 0.1 percentage points, but remain statistically significant. Standard errors reported in Table 2 are clustered at a policy level. ${ }^{4}$

\section{INSERT TABLE 2}

Panel 1 of Table 2 provides the reduced form estimates of the effect of the drinking law regulation in Spain on worker absenteeism. Again we report separate OLS estimates for minutes difference and Tobit estimates for the absence rate. The initial estimates (first 3 columns) contain standard controls which are again suppressed for brevity, and year, quarter and region fixed effects. These estimates suggest a link between shorter drinking hours and reduced absenteeism, however the estimates are not statistically significant at standard levels.

We extend these initial specifications in both countries by including region specific quarterly time trends in addition to region, quarter and year fixed effects. The resultant estimates are reported in Panel 2 of Tables 1 and 2. The results for both the UK and Spain appear robust to controlling for violations in the common trends assumption. In both cases introducing these trends lead to an increase in the estimated impact of the policy, leading to estimates in Spain that remain negative but are now statistically different from zero. This model that allows for regional variation in absence time trends is our preferred specification and all subsequent reported estimates will be based on this. For brevity, we omit the OLS estimates of the absence rate from this point on, but these are available from the authors upon request.

Due to the pattern of bar attendance, which is likely to be more concentrated among young people, we may expect treatment heterogeneity according to the age of workers. This may be amplified in the Spanish case due to the margin at which the legislative adjustment was made, young people are not only more likely to attend bars, but more likely to attend bars up to 6 am prior to the reform. This second effect may be less marked in the case of England and Wales due to the change being from $11 \mathrm{pm}$. We re-estimated our main models for across different age groups, marital status and gender. These results are available as

\footnotetext{
${ }^{4}$ We compare the p-value that corresponds to this standard error (p-value: 0.0070$)$ with the p-value when we implement a Wild Bootstrap Procedure with assignment at the policy level (p-value $=0.000$ ). In the Wild Bootstrap Procedure we use the Rademarcher distribution and set the number of replications to 400. The p-value of 0.000 indicates that we can reject the null hypothesis of no policy effect on absenteeism.
} 
online appendix Table A3. For England and Wales this suggests that the policy effect was concentrated amongst younger, male and unmarried workers. For Spain, policy effects are somewhat larger for male and unmarried workers but there is a less clear age gradient.

Finally, in the case of Spain there is time variation in hours restrictions and this allows us to estimate a model with differential treatment intensity and thus the effect of an additional hour's restriction on absenteeism. In unreported estimates we find that an additional hour's reduction in opening reduces absence by 6 minutes or 1.9 percentage points.

To provide an estimate of the economic magnitude of these effects we use the population weights available in the UK-LFS and SLFS to calculate the number of affected workers. In both cases we use our estimating sample and restrict the population to the treated areas (England/Wales and the 11 regions that implement reduced hours in Spain). We then take corresponding hourly wage information from the UK-LFS, and in the case of Spain, the Wage Structure Survey 2002 as the SLFS does not contain wage information. Converting our minutes absence to hourly absence allows to compute a gain in productivity of approximately 37.7 million euros p.a. for Spain and a loss of productivity of 47.5 million pounds p.a. for England/Wales solely due to absence variation.

\section{Threats to Identification and Inference}

Our results demonstrate that drinking law regulations have the potential to influence worker absenteeism. A strength of our approach is that the effect is found for two different countries where the policy was operating in different directions. Nonetheless, in this section we examine a range of potential threats to our identification strategy, and in turn discuss standard concerns with inference in a difference in difference setting.

\section{INSERT TABLE 3}

First, our current estimates include all workers irrespective of working hours. Parttime workers have hours of work that naturally vary and this may bias our policy estimates. The first row of Table 3 provides estimates where our samples are restricted to full-time workers only. The resultant point estimates are essentially unchanged. Second, our measures of absenteeism may be too broad as they capture all variations in working time, including those that occur for reasons out of the control of workers. Using information in the UK LFS and SLFS on reasons for variation of working hours we exclude categories that were less 
likely to be in the control of workers. Again the policy estimates are essentially unchanged. Insofar as the remaining reasons for absence (such as sickness, personal and family reasons and 'other' reasons) can be more readily controlled by workers this makes us more confident that our estimates are picking up worker responses to changes in drinking hours. Finally, some variation in working hours may result from either workers taking a vacation, or bank holidays or (in the case of Spain) a local festival falling in the reference week. Again we exclude observations where variations in time worked are reported to be due to these factors. As reported in Table 3 doing so does not markedly change our key estimates, although there is some loss of precision in the case of Spain in the most restrictive model.

One might think that any effects of alcohol availability and consumption on absence would be concentrated in shorter absence spells. We re-estimated our main models excluding any workers with absence spells beyond 1 day of standard working hours. These are reported in Table 4. There is some diminution of magnitude but these remain suggestive of an effect of alcohol availability on shorter term absence. While these are not definitive they do however provide an indication that at least our results remain in these specifications and hence our main results are not solely due to long periods of absence less likely to be directly related to bar attendance behaviour over the short run. One caution we add is that while work absence due to the direct intoxication effects of the previous night's drinking, alcohol availability may influence longer spells of absence through other issues such as injury, poor health and criminal victimisation.

We next investigate the sensitivity of our results to a range of issues related to regional variation in the timing of implementation and the extent of expansion. Unlike Spain, the change in licensing in England and Wales was, in effect, not mandatory. Individual venues had to apply for an additional licence to remain open later. This leads to potential variation in the intensity of treatment. In areas where there is a greater density of venues that increased hours, we might expect a larger absence response. The UK Department for Culture, Media and Sport reports the number of licenses granted by region. Most regions have quite a similar density of extended hours licences per head of population (18 years or older) of between 0.94 licenses per thousand people and 1.47 per thousand people. However, three regions have particularly high densities, the South West of England, London and the North East of England (1.47, 1.44 and 1.25, respectively). We re-estimated our models for these regions only (again using Scotland and Northern Ireland as control groups) and these reveal 
higher estimates of the policy effect than those for England and Wales in total. Nonetheless, there is still a statistically significant policy effect for the other, lower density, regions. These results suggest that the overall policy effect does not purely reflect non-random adoption across regions.

Another concern may be that border crossing between England and Scotland to consume alcohol could contaminate our results. The Anglo-Scottish border is sparsely populated and this suggests that border crossing is unlikely to be a major factor in our estimates. Nonetheless we re-estimated our models excluding the regions in England bordering Scotland (Tyne and Wear and Rest of the Northern Region) and our main estimates were unaffected.

In the case of Spain, there was discretion in the timing of the adoption of the policy. Regions where there were more marked problems related to extended drinking hours may have adopted the policy early and this may bias our results. We re-estimated our main models up to 2002 such that our policy estimate is only for those three regions that adopted early, La Rioja, Balearic Islands and the Basque Country. The estimates for these early adopters are much higher than our main results. This provides a first indication of non-random adoption of reduced hours in Spain.

We next examine whether the policy effect on absence behaviour was short-lived or long-lasting. The initial approach taken is to simply exclude the year of reform from our sample. In the case of Spain the excluded year varies by region due to the differential timing of reform, while for the UK this amounts to removing the $24^{\text {th }}$ of November 2005 to the $23^{\text {rd }}$ of November 2006. For the UK there is essentially no difference between the resultant estimates and our previous results. This suggests an effect of extending hours that does not immediately diminish and therefore fits with the pattern of absence observed in Figure 1. For Spain, however, the policy effect essentially halves in magnitude and is no longer statistically significant at standard levels.

\section{INSERT FIGURE 3}

While our results for Spain are robust to including region specific linear time trends, the fact that the policy effect is bigger for early adopters and that our results are not statistically significant when omitting the year of policy implementation is suggestive of a short term policy effect that may be concentrated in early adopters. This is investigated 
further by using a regression-adjusted event study in the spirit of Autor (2003). The key estimates are presented pictorially as Figure 3 with 95\% confidence intervals around the point estimates. The regression that generates these estimates is our main specification where the policy indicator is replaced by a series of leads and lags. There are two striking features of the resultant pattern. First, there is some evidence of anticipation. There is a reduction in absenteeism in the year prior to adoption that is statistically different from zero at the 5\% level. Nonetheless the majority of the reduction occurs in the year of implementation and the year afterwards. Both of these estimates are statistically different from zero at the $5 \%$ level. The estimates for these two years are also statistically different from that of the year prior to implementation. The other clear result is that the absence 'benefits' from shorter opening hours disappear completely within 2 years. Hence, workers in Spain respond to shorter opening hours in the short run with less absenteeism but there is no long term effect.

\section{INSERT TABLE 4}

In Table 4 we pursue a number of further robustness checks which relate specifically to the UK. First, one advantage of our UK data is the ability to introduce worker fixed effects. This allows us to examine the potential for our estimates to be influenced by compositional change in the workforce pre and post policy. Worker level fixed effects are introduced into our main specification and reported in Table 4. The resultant estimates demonstrate again that the extension of drinking hours substantially affects worker absence behaviour.

A general concern relates to whether workers in Scotland and Northern Ireland provide a good counter-factual for workers in England and Wales. We investigated this further using a synthetic control method in the spirit of Abadie and Gardeazabal (2003). This method consists on comparing the absence series of the treatment group (England and Wales) with a synthetic absence series for the control group (Scotland and Northern Ireland). ${ }^{5}$ The synthetic control series is built as a weighted average of absence behaviour for the different geographic areas in the control group (Strathclyde, the rest of Scotland and Northern Ireland) in such a way that the synthetic England/Wales or synthetic control group (minutes absence = 389.46; absence rate $=18.49$ ) more closely resembles the actual England/Wales series (minutes absence rate $=392.10$; absence rate $=18.67$ ) before the extension of opening hours.

\footnotetext{
${ }^{5}$ This is not the ideal data with which to implement this method. While there is a significant population in our control groups (approximately 5,094,800 in Scotland and 1,724,400 in Northern Ireland) the LFS only provides three identifiable regions for these geographic areas (Strathclyde, the rest of Scotland and Northern Ireland).
} 
For the minutes absence models the optimal weights for Strathclyde, the rest of Scotland and Northern Ireland are $0.873,0$ and 0.127 respectively. The optimal weights for the absence rate model are 0, 0.931 and 0.069 for Strathclyde, rest of Scotland and Northern Ireland respectively. The resulting estimates are larger than before, but with a loss of precision. These estimates are 35.19 minutes absence and 0.008 increase in the absence rate, where the absence rate is estimated via OLS.

A standard concern with DD estimates in repeated cross-sections with a long time dimension is that if there is serial correlation in the dependent variable this leads to standard errors that are biased downwards and hence incorrect inference (Bertrand, Duflo and Mullainathan, 2004). To examine this we collapse our UK data by individual into two periods, pre and post reform. We then re-estimate equation (1) on this collapsed data and the results which remain positive and statistically significant at the $1 \%$ level are reported in Table 4.

\section{Transmission Mechanisms}

In practice, the effect of opening hours on absence could occur through a variety of channels. For instance, the proximity of hours of leisure consumption and work could influence worker absence decisions. Likewise, increases in alcohol consumption or consumption more proximate to working hours could spill-over into working hours. In this section, we use a variety of approaches for the UK to provide suggestive evidence on the role of alcohol consumption as a factor linking opening hours and absenteeism. Corresponding evidence for Spain is not provided for two main reasons. The first reflects the lack of a longterm robust effect demonstrated in the previous section. The second is more pragmatic, there is simply a lack of data that allows us to pursue this line of investigation for Spain. ${ }^{6}$

Alcohol consumption could change with opening hours in the form of more consumption by those who attend licensed venues, or due to a change in venue attendance behaviour. Using representative UK data we explore both. We use the Expenditure and Food Survey (EFS) data from 2001-2007 and the Living Costs and Food Survey 2008 which provides a representative sample of household's expenditure in the UK as an annual repeated cross-section. This data asks respondents to keep a two week diary detailing expenditure

\footnotetext{
${ }^{6}$ A Spanish FES equivalent exists. However a lack of consistent data on the particular expenditure group of interest across our policy period means that we cannot estimate the policy impact on alcohol expenditure at drinking establishments in Spain.
} 
items and the value of purchases. In particular, it provides information on expenditure on alcohol at licensed premises (i.e. bars, hotels and restaurants) at a household level.

This expenditure information is used to estimate a simple analogue of our differencein-difference model for the UK with log alcohol expenditure per week (f) at licensed venues as the dependent variable. Extending bar hours increased alcohol expenditure on-premises by 6.8\% for individuals living in England and Wales compared to those living in Scotland and Northern Ireland (Table 5). This provides evidence that greater on-premise availability increases alcohol expenditure. This is in line with previous evidence of the effect of offpremise availability on consumption provided by Carpenter and Eisenberg (2009). Moreover, our estimates are broadly similar in magnitude to the $7 \%-15 \%$ found in their study of Sunday trading in Canada. While they found that Sunday drinking increased as a result of greater availability, overall weekly alcohol consumption did not appear to increase. Sunday drinking was matched by reductions in drinking on other days. In our case, we estimated the effect of the increase in opening hours on off-premise alcohol expenditure, also available in the EFS. In unreported estimates, we found no effect on this expenditure. Hence, our results do not seem to reflect substitution of drinking between on and off premises.

\section{INSERT TABLE 5}

Another channel through which longer opening hours could influence drinking behaviour is directly through frequency of bar attendance. The British Household Panel Survey (BHPS) contains information on how often on average the interviewee goes out to licensed venues to drink. As the BHPS contains longitudinal data for England/Wales and Scotland and Northern Ireland we can use this information to estimate a difference-indifference model where frequency of going out to licensed venues is the dependent variable. Specifically, we construct the variable drink often which takes value 1 if the individual declares that they go out to licensed venues to drink several times a year, at least once a month and at least once a week and 0 if the individual goes out to licensed venues either once a year or less or never/almost never. These estimates suggest that extending bar hours increases the probability of going out for a drink in England and Wales by $1.2 \%$ compared to Scotland and Northern Ireland. 


\section{Conclusion}

This paper sought to examine how changes in permissible bar opening hours influences individual labour supply decisions. Specifically, we used two recent changes in the legal opening hours of licensed premises in England and Wales and Spain. These are particularly advantageous insofar as they provide policy changes in opposite directions, an extension in drinking hours in England and Wales and a reduction in Spain. Focusing on one dimension of intra-marginal labour supply, absenteeism, we demonstrate a causal effect of these legislative changes. Increasing opening hours in England and Wales increased worker absenteeism, whilst reducing opening hours in Spain reduced absenteeism. This result appears robust to a range of standard threats to identification for the UK where we provide further evidence that suggests that the channel of transmission is through an increase in alcohol consumption. The effect for Spain, however, disappears after 2 years of implementation. This suggests that the 'benefits' from shorter opening hours in terms of less absenteeism are short-lived.

This result contributes to the growing literature on the labour market consequences of alcohol availability. It provides the first evidence, specifically, that more availability in terms of opening hours of licensed premises has an effect on worker absence behaviour. In addition, we contribute to existing evidence that availability influences alcohol consumption. Finally, our results suggest that government intervention in the regulation of leisure activities has the potential to have unintended consequences on worker behaviour and workplace productivity. 


\section{References}

Abadie, A. and Gardeazabal, J. (2003). 'The Economic Costs of Conflict: A Case Study of the Basque Country', American Economic Review, Vol. 93, pp. 113-132.

Anderson, P. Chisholm, D. and Fuhr, D. (2009) 'Effectiveness and cost-Effectiveness of Policies and Programmes to Reduce the Harm Caused by Alcohol', Lancet, Vol. 373, pp. 2234-2246.

Audas, R. Barmby, T. and Treble, J. (2004). 'Luck, Effort and Reward in an Organisational Hierarchy'. Journal of Labor Economics, Vol. 22, pp. 379-396.

Autor, D. (2003) 'Outsourcing at Will: The Contribution of Unjust Dismissal Doctrine to the Growth of Employment Outsourcing' Journal of Labor Economics, Vol. 21, pp. 1-42.

Ayres, I. and Levitt, S. (1998). 'Measuring Positive Externalities from Unobservable Victim Precaution: An Empirical Analysis of Lojack', Quarterly Journal of Economics, Vol. 113, pp. 43-77.

Balsa, A. and French, M. (2010). 'Alcohol Use and the Labor Market in Uruguay', Health Economics, Vol. 19, pp. 833-854.

Barmby, T. Orme, C. and Treble, J. (1991). 'Worker Absenteeism: An Analysis using Microdata', Economic Journal, Vol. 101, pp. 214-229.

Barmby, T. Ercolani, M. and Treble, J. (2002). 'Sickness Absence: An International Comparison', Economic Journal, Vol. 112, pp. F315-F331.

Bernheim, BD Meer, J and Novarro, N. (2012). 'Do Consumers Exploit Precommitment Opportunities? Evidence from Natural Experiments Involving Liquor Consumption', NBER Working Paper 17762.

Bertrand, M. Duflo, E. and Sendhil, M. (2004). 'How Much Should We Trust Differences-inDifferences Estimates?', Quarterly Journal of Economics, Vol. 119, pp. 249-275.

Biddle, J. and Hamermesh, D. (1990). 'Sleep and the Allocation of Time', Journal of Political Economy, Vol. 98, pp. 922-943.

Biderman, C. De Mello, J. and Schneider, A. (2010). 'Dry Laws and Homicides: Evidence from the Sao Paulo Metropolitan Area', Economic Journal, Vol. 120, pp. 157-182. 
Blundell, R. Duncan, A. and Meghir, C. (1998). 'Estimating Labor Supply Responses Using Tax Reforms', Econometrica, Vol. 66(4), pp. 827-861.

Bradley, S. Green, C. and Leeves, G. (2014) 'Employment Protection, Threat and Incentive Effects on Worker Absence', British Journal of Industrial Relations, Vol. 52, pp. 333-358.

Burtless, G. and Hausman, J. (1978) 'The Effect of Taxation on Labor Supply: Evaluating the Gary Negative Income Tax Experiment', Journal of Political Economy, Vol. 86, pp. 11031130

Cameron, C. Gelbach, J. and Miller, D. (2008). 'Bootstrap-based improvements for inference with clustered errors', The Review of Economics and Statistics, Vol. 90, pp. 414-427.

Carpenter, C. and Dobkin, C. (2011a) 'The Minimum Legal Drinking Age and Public Health', Journal of Economic Perspectives, Vol. 25, pp. 133-156.

Carpenter, C. and Dobkin, C. (2011b). 'Alcohol Regulation and Crime', NBER Working Paper 15828.

Carpenter, C. and Eisenberg, D. (2009). 'Effects of Sunday Sales Restrictions on Overall and Day-Specific Alcohol Consumption: Evidence From Canada', Journal of Studies on Alcohol and Drugs, Vol. 70, pp. 126-133.

Chikritzhs, T. and Stockwell, T. (2002). 'The Impact of Later Trading Hours for Australian Public Houses (hotels) on Levels of Violence", Journal of Studies on Alcohol, Vol. 63, pp. 591-599.

Dave, D. and Kaestner, R. (2002). 'Alcohol Taxes and Labor Market Outcomes', Journal of Health Economics, Vol. 21, pp. 357-371.

Green, C. Heywood, J. and Navarro, M. (2014). 'Did Liberalizing Bar Hours Decrease Traffic Accidents?', Journal of Health Economics, Vol. 35, pp. 189-198.

Green, C. and Navarro, M. (2012). 'Does Raising the School Leaving Age Reduce Teacher Effort? Evidence from a Policy Experiment', Economic Inquiry, Vol. 50, pp. 1018-1030.

Grönqvist, H. and Niknami, S. (2014). 'Alcohol Availability and Crime: Lessons from Liberalized Weekend Sales Restrictions', Journal of Urban Economics, Vol. 81, pp. 77-84.

Heaton, P. (2012). 'Sunday liquor laws and crime', Journal of Public Economics, Vol. 96, pp. 42-52. 
Hough, M. and Hunter, G. (2008). 'The 2003 Licensing Act's impact on crime and disorder: An evaluation', Criminology and Criminal Justice, Vol. 8, pp. 239-260.

Humphreys, D. and Eisner, M. (2010). 'Evaluating a natural experiment in alcohol policy: The Licensing Act (2003) and the requirement for attention to implementation', Criminology \& Public Policy, Vol. 9, pp. 41-67.

IAS (2007). 'Crime \& Disorder; binge drinking and the Licensing Act', Institute of Alcohol Studies (IAS) Occasional Paper.

Ichino, A. and Riphahn, R. (2005). 'The effect of employment protection on worker effort: Absenteeism during and after probation', The Journal of the European Economic Association, Vol. 3, pp. 120-143.

Johansson, P. Pekkarinen, T. and Verho, J. (2014). 'Cross-Border Health and Productivity Effects of Alcohol Policies', Journal of Health Economics, Vol. 36, pp. 125-136.

Johansson, E. Bockerman, P. and Uutela, A. (2008). 'Alcohol Consumption and Sickness Absence: Evidence from Microdata', European Journal of Public Health, Vol. 19, pp. 19-22. Lozano, F. (2010). 'The Flexibility of the Workweek in the United States: Evidence from the FIFA World Cup', Economic Inquiry, Vol. 49, pp. 512-529.

Norstrom, T. (2006). 'Per capita alcohol consumption and sickness absence', Addiction, Vol. 110, pp. 1421-1427.

Smith, D. (1990). 'Effect on Casualty Traffic Accidents of Changing Sunday Alcohol Sales Legislation in Victoria, Australia', Journal of Drug Issues, Vol. 20, pp. 417-426.

Vingilis, E. McLeod, A. Seeley, J. Mann, R. Beirness, D. and Compton, C. (2005). 'Road safety impacts of extending drinking hours in Ontario', Accident Analysis and Prevention, Vol. 37, pp. 549-556. 
FIGURE 1

Minutes of absence for workers in the UK

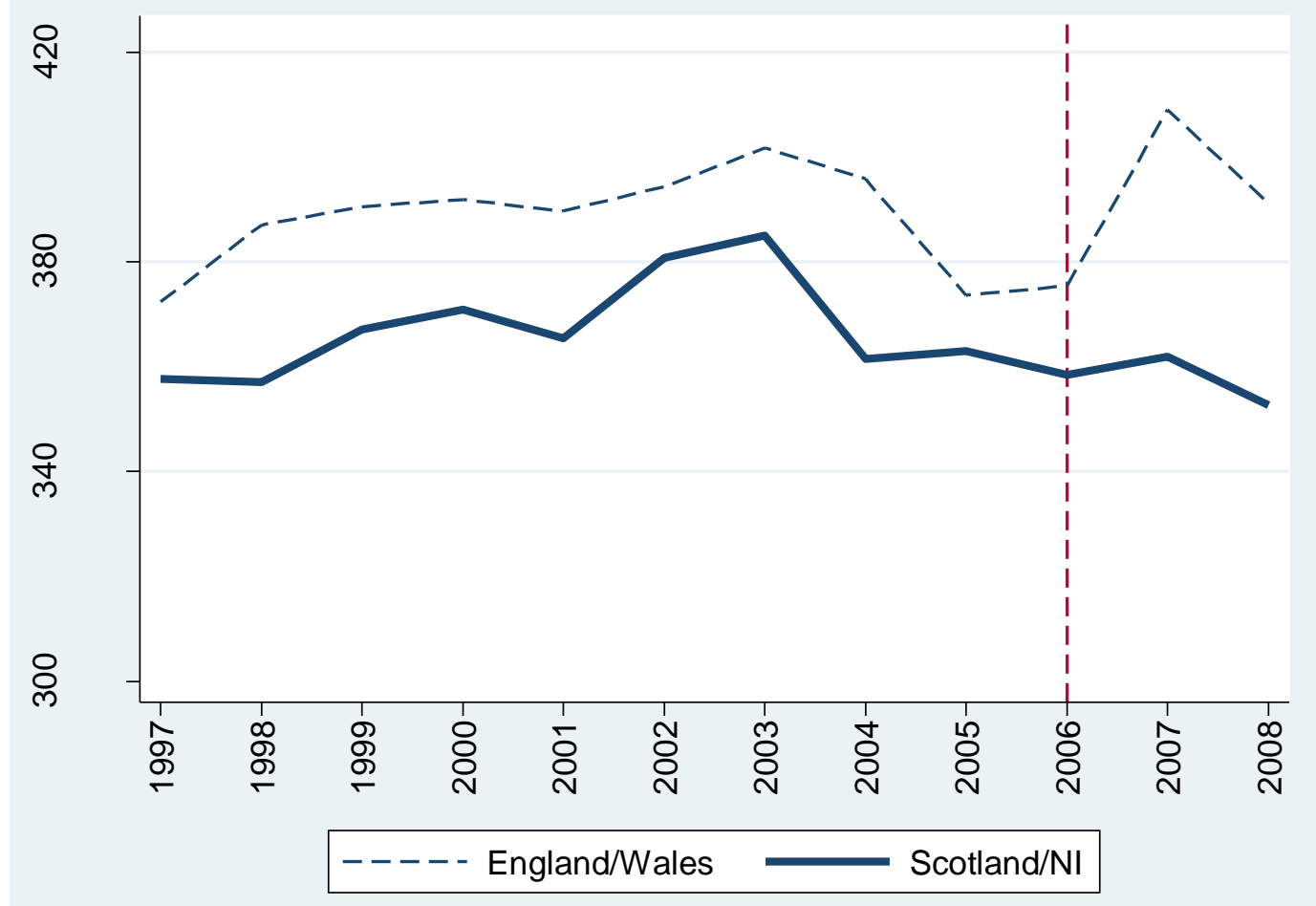


FIGURE 2

Minutes of absence for workers in Spain

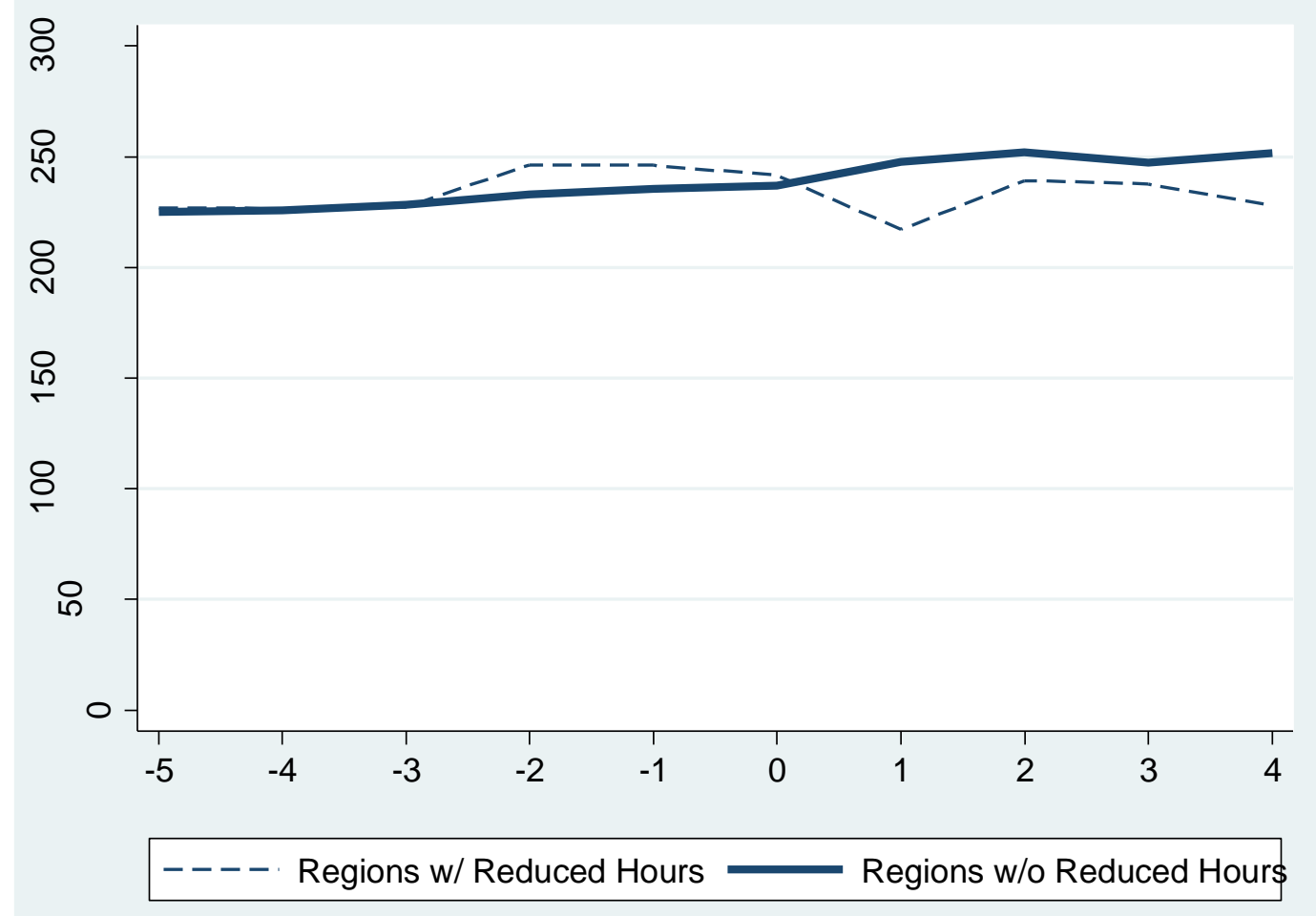




\section{FIGURE 3}

Estimated impact of extending opening hours on minutes absence in Spain for years before, during and after adoption.

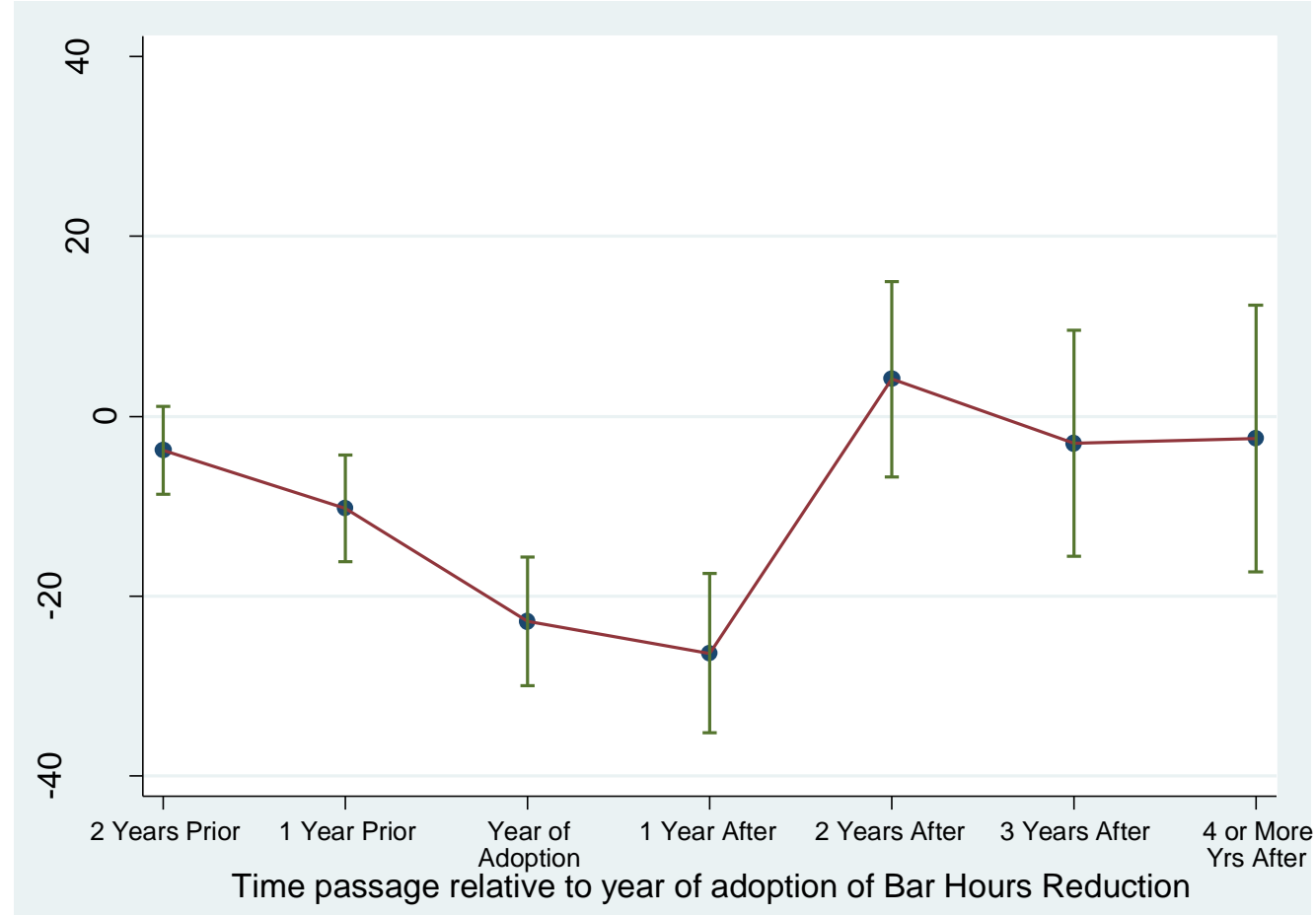


TABLE 1.

Effect of licensing laws on absence behaviour in the UK, 1997-2008

\begin{tabular}{|c|c|c|c|c|c|c|}
\hline & \multicolumn{3}{|c|}{ Panel 1} & \multicolumn{3}{|c|}{ Panel 2} \\
\hline & Minutes Absence & $\begin{array}{c}\text { Absence Rate } \\
\text { (Tobit) }\end{array}$ & $\begin{array}{c}\text { Absence Rate } \\
(O L S)\end{array}$ & Minutes Absence & $\begin{array}{c}\text { Absence Rate } \\
\text { (Tobit) }\end{array}$ & $\begin{array}{c}\text { Absence Rate } \\
(O L S)\end{array}$ \\
\hline Policy & $\begin{array}{c}5.590 * * * \\
(0.062)\end{array}$ & $\begin{array}{c}0.014 * * * \\
(0.000)\end{array}$ & $\begin{array}{c}0.001 * * \\
(0.000)\end{array}$ & $\begin{array}{c}10.855^{* * *} \\
(0.199)\end{array}$ & $\begin{array}{c}0.026 * * * \\
(0.001)\end{array}$ & $\begin{array}{c}0.003 * * \\
(0.000)\end{array}$ \\
\hline Female & $\begin{array}{c}47.557 * * \\
(2.109)\end{array}$ & $\begin{array}{c}0.065^{* * * *} \\
(0.006)\end{array}$ & $\begin{array}{c}0.032 * * \\
(0.001)\end{array}$ & $\begin{array}{c}47.563 * * \\
(2.118)\end{array}$ & $\begin{array}{c}0.065^{* * *} * \\
(0.006)\end{array}$ & $\begin{array}{c}0.032 * * \\
(0.001)\end{array}$ \\
\hline Degree or higher & $\begin{array}{c}35.577 * * \\
(1.375)\end{array}$ & $\begin{array}{c}0.072 * * * \\
(0.007)\end{array}$ & $\begin{array}{l}0.013^{*} \\
(0.001)\end{array}$ & $\begin{array}{c}35.579 * * \\
(1.378)\end{array}$ & $\begin{array}{c}0.072 * * * \\
(0.007)\end{array}$ & $\begin{array}{l}0.013^{*} \\
(0.001)\end{array}$ \\
\hline Vocational training/Diploma & $\begin{array}{c}32.737 * * * \\
(0.396)\end{array}$ & $\begin{array}{c}0.075^{* * * *} \\
(0.006)\end{array}$ & $\begin{array}{c}0.015^{* *} \\
(0.000)\end{array}$ & $\begin{array}{c}32.733 * * * \\
(0.400)\end{array}$ & $\begin{array}{c}0.075^{* * * *} \\
(0.006)\end{array}$ & $\begin{array}{c}0.015^{* *} * \\
(0.000)\end{array}$ \\
\hline A-Levels & $\begin{array}{c}25.320 * * \\
(0.652)\end{array}$ & $\begin{array}{c}0.052 * * * \\
(0.002)\end{array}$ & $\begin{array}{c}0.011 * * \\
(0.000)\end{array}$ & $\begin{array}{c}25.328 * * \\
(0.640)\end{array}$ & $\begin{array}{c}0.052 * * * \\
(0.002)\end{array}$ & $\begin{array}{c}0.011^{* *} \\
(0.000)\end{array}$ \\
\hline Temporary contract & $\begin{array}{c}-36.528^{* *} \\
(2.814)\end{array}$ & $\begin{array}{c}0.008 \\
(0.013)\end{array}$ & $\begin{array}{c}0.011 \\
(0.004)\end{array}$ & $\begin{array}{c}-36.530 * * \\
(2.818)\end{array}$ & $\begin{array}{c}0.008 \\
(0.013)\end{array}$ & $\begin{array}{c}0.011 \\
(0.004)\end{array}$ \\
\hline Public sector & $\begin{array}{c}65.960 * * * \\
(0.781)\end{array}$ & $\begin{array}{c}0.097 * * * \\
(0.004)\end{array}$ & $\begin{array}{c}0.035 * * * \\
(0.000)\end{array}$ & $\begin{array}{c}65.960 * * * \\
(0.781)\end{array}$ & $\begin{array}{c}0.097 * * * \\
(0.004)\end{array}$ & $\begin{array}{c}0.035^{* * * *} \\
(0.000)\end{array}$ \\
\hline Region FE & Yes & Yes & Yes & Yes & Yes & Yes \\
\hline Year FE & Yes & Yes & Yes & Yes & Yes & Yes \\
\hline Quarterly dummies & Yes & Yes & Yes & Yes & Yes & Yes \\
\hline Quarterly Trend * region & No & No & No & Yes & Yes & Yes \\
\hline Observations & 846106 & 846106 & 846106 & 846106 & 846106 & 846106 \\
\hline
\end{tabular}


TABLE 2.

Effect of licensing laws on worker absence behaviour in Spain, 1997-2007

\begin{tabular}{|c|c|c|c|c|c|c|}
\hline & \multicolumn{3}{|c|}{ Panel 1} & \multicolumn{3}{|c|}{ Panel 2} \\
\hline & Minutes Absence & $\begin{array}{c}\text { Absence Rate } \\
\text { (Tobit) }\end{array}$ & $\begin{array}{c}\text { Absence Rate } \\
(\text { OLS })\end{array}$ & Minutes Absence & $\begin{array}{c}\text { Absence Rate } \\
\text { (Tobit) }\end{array}$ & $\begin{array}{c}\text { Absence Rate } \\
(O L S)\end{array}$ \\
\hline Policy & $\begin{array}{l}-3.424 \\
(4.631)\end{array}$ & $\begin{array}{c}-0.009 \\
(0.017)\end{array}$ & $\begin{array}{c}-0.001 \\
(0.002)\end{array}$ & $\begin{array}{c}-17.616^{* *} \\
(7.502)\end{array}$ & $\begin{array}{c}-0.053 * * \\
(0.021)\end{array}$ & $\begin{array}{c}-0.008 * * \\
(0.003)\end{array}$ \\
\hline \multirow[t]{2}{*}{ Female } & $35.089 * * *$ & $0.144 * * *$ & $0.025 * * *$ & $34.891 * * *$ & $0.144 * * *$ & $0.025 * * *$ \\
\hline & $(3.751)$ & $(0.011)$ & $(0.002)$ & $(3.507)$ & $(0.010)$ & $(0.002)$ \\
\hline \multirow[t]{2}{*}{ Secondary education } & -1.977 & -0.001 & -0.001 & -1.369 & -0.001 & -0.000 \\
\hline & $(2.114)$ & $(0.007)$ & $(0.001)$ & $(2.098)$ & $(0.007)$ & $(0.001)$ \\
\hline \multirow[t]{2}{*}{ Higher education } & $8.138 * * *$ & $0.027 * * *$ & $0.003 * * *$ & $8.572 * * *$ & $0.024 * * *$ & $0.003 * * *$ \\
\hline & $(2.395)$ & $(0.009)$ & $(0.001)$ & $(2.202)$ & $(0.008)$ & $(0.001)$ \\
\hline \multirow[t]{2}{*}{ Public sector } & $74.096 * * *$ & $0.178 * * *$ & $0.033 * * *$ & $75.900 * * *$ & $0.185^{* * *}$ & $0.034 * * *$ \\
\hline & $(3.297)$ & $(0.011)$ & $(0.002)$ & $(3.226)$ & $(0.010)$ & $(0.001)$ \\
\hline \multirow[t]{2}{*}{ Temporary contract } & $-52.586^{* * *}$ & $-0.127 * * *$ & $-0.022 * * *$ & $-51.758 * * *$ & $-0.129 * * *$ & $-0.021 * * *$ \\
\hline & $(2.524)$ & $(0.008)$ & $(0.001)$ & $(2.487)$ & $(0.008)$ & $(0.001)$ \\
\hline Region FE & Yes & Yes & Yes & Yes & Yes & Yes \\
\hline Year FE & Yes & Yes & Yes & Yes & Yes & Yes \\
\hline Quarterly dummies & Yes & Yes & Yes & Yes & Yes & Yes \\
\hline Quarterly Trend * region & No & No & No & Yes & Yes & Yes \\
\hline Observations & 1993260 & 1993260 & 1993260 & 1993260 & 1993260 & 1993260 \\
\hline
\end{tabular}


TABLE 3.

Robustness checks, UK and Spain

\begin{tabular}{|c|c|c|c|c|}
\hline & \multicolumn{2}{|c|}{ United Kingdom } & \multicolumn{2}{|c|}{ Spain } \\
\hline & Minutes difference & Absence rate & Minutes difference & Absence rate \\
\hline Full time workers only & $\begin{array}{c}11.678 * * \\
(0.356)\end{array}$ & $\begin{array}{c}0.033 * * * \\
(0.002)\end{array}$ & $\begin{array}{c}-17.973 * * \\
(7.658)\end{array}$ & $\begin{array}{c}-0.054 * * * \\
(0.021)\end{array}$ \\
\hline Narrower Absence Definition & $\begin{array}{c}12.190 * * * \\
(0.143)\end{array}$ & $\begin{array}{c}0.049 * * * \\
(0.003)\end{array}$ & $\begin{array}{c}-17.544 * * \\
(7.574)\end{array}$ & $\begin{array}{c}-0.057 * * * \\
(0.022)\end{array}$ \\
\hline Excluding Vacations & $\begin{array}{c}14.372 * * \\
(0.294)\end{array}$ & $\begin{array}{c}0.033 * * * \\
(0.001)\end{array}$ & $\begin{array}{c}-23.163^{*} \\
(11.317)\end{array}$ & $\begin{array}{c}-0.138^{*} \\
(0.083)\end{array}$ \\
\hline Excluding Vacations, Bank Holidays/Local Festivals & $\begin{array}{c}14.853 * * * \\
(0.190)\end{array}$ & $\begin{array}{c}0.034 * * * \\
(0.001)\end{array}$ & $\begin{array}{c}-9.178^{*} \\
(4.399)\end{array}$ & $\begin{array}{l}-0.072 \\
(0.101)\end{array}$ \\
\hline Absence of $<=1$ day & $\begin{array}{c}5.565^{* * * *} \\
(0.025)\end{array}$ & $\begin{array}{c}0.014 * * * \\
(0.001)\end{array}$ & $\begin{array}{c}-3.937^{*} \\
(2.212)\end{array}$ & $\begin{array}{l}-0.012 \\
(0.010)\end{array}$ \\
\hline Regions with high proportion of licences & $\begin{array}{c}27.267 * * * \\
(0.425)\end{array}$ & $\begin{array}{c}0.048 * * * \\
(0.004)\end{array}$ & & \\
\hline Regions with low proportion of licences & $\begin{array}{c}5.534 * * \\
(0.208)\end{array}$ & $\begin{array}{c}0.020 * * * \\
(0.001)\end{array}$ & & \\
\hline Exclude Border Regions & $\begin{array}{c}11.769 * * * \\
(0.182)\end{array}$ & $\begin{array}{c}0.027 * * * \\
(0.001)\end{array}$ & & \\
\hline Early Adopters & & & $\begin{array}{l}-53.261^{*} \\
(29.837)\end{array}$ & $\begin{array}{l}-0.176^{*} \\
(0.101)\end{array}$ \\
\hline Exclude year of policy implementation & $\begin{array}{c}10.855^{* * *} \\
(0.199)\end{array}$ & $\begin{array}{c}0.026 * * * \\
(0.001)\end{array}$ & $\begin{array}{l}-9.986 \\
(8.877)\end{array}$ & $\begin{array}{l}-0.029 \\
(0.029)\end{array}$ \\
\hline
\end{tabular}

Notes: All other controls as per Tables 2 and 3. All models include region, quarter and year fixed effects along with the interaction of the quarterly time trend with regional dummies. $* * *$, and $* * *$ indicate statistical significance at the $10 \%$, the $5 \%$, and the $1 \%$ levels, respectively. 
TABLE 4.

Further robustness tests, $U K$.

\begin{tabular}{lcc}
\hline & Minutes Difference & Absence Rate \\
\hline & $47.250^{* * *}$ & $0.013^{* * *}$ \\
Worker FE & $(0.313)$ & $(0.000)$ \\
& $35.193^{* *}$ & $0.008^{* *}$ \\
Synthetic Cohort & $(16.095)$ & $(0.004)$ \\
Collapsed Sample & $14.407 * * *$ & $0.015^{* * *}$ \\
& $(0.012)$ & $(0.000)$
\end{tabular}

Notes: Worker FE, and Placebo models include all controls as per Table 2 along with region, quarter and year fixed effects along with the interaction of the quarterly time trend with regional dummies. *, **, and $* * *$ indicate statistical significance at the $10 \%$, the $5 \%$, and the $1 \%$ levels, respectively. 


\section{TABLE 5}

Effect of licensing laws on alcohol expenditure outside the household per week and the probability of going out to licensed venues to drink

\section{EFS: $\log ($ alcexp) $\quad$ BHPS: Drink often}

$\begin{array}{lcc}\text { DD } & 0.068 * * & 0.012 * * * \\ & (0.029) & (0.004) \\ \text { Treatment } & -0.096 * * * & 0.039 * * * \\ & (0.019) & (0.006) \\ \text { Policy } & 0.155 * * * & -0.007 * * \\ & (0.027) & (0.003)\end{array}$

Observations

42523

139184 